\title{
Pelatihan dan Pemberdayaan Wali Siswa dalam Upaya Peningkatan Derajat Kesehatan Status Gizi Pada Anak
}

\author{
Maulida Nurfazriah O, Rizki Yulia P \\ Prodi DIII Keperawatan Akademi Kesehatan RUSTIDA, Banyuwangi \\ Octavia.lieda@yahoo.com
}

\begin{abstract}
Abstrak
Pemberian pelatihan dan pemberdayaan wali siswa dalam pemberian makanan sehat merupakan upaya untuk meningkatkan derajat kesehatan status gizi pada anak sejak dini. Anak usia dini sangat rentan terserang berbagai macam penyakit terutama yang berasal dari makanan, sehingga diperlukan pengawasan terutama orang tua dalam menyediakan makan untuk anak agar anakanak tidak mudah terserang penyakit.Tujuan kegiatan ini adalah untuk meningkatkan pengetahuan orang tua tentang cara pengolahan makanan yang sehat dan bergizi bagi anak, serta meningkatkan keterampilan dalam menyiapkan atau menyajikan makanan (bekal sekolah anak). Metode kegiatan ini adalah bekerjasama dengan dinas terkait yang sangat berperan dalam menginformasikan diadakannya Pengabdian Kepada Masyarakat (PKM) tentang peningkatan derajat kesehatan status gizi pada anak. Sosialisasi pada wali siswa tentang cara pengolahan makanan dan menyiapakan makanan yang baik. Untuk menunjang keberhasilan PKM melibatkan guru taman kanak-kanak. Hasil kegiatan ini menunjukkan peningkatan pengetahuan wali siswa cara pengolahan makanan yang sehat dan bergizi bagi anak, bahwa $75 \%$ mendapatkan nilai tinggi. Dan meningkatkan keterampilan dalam menyiapkan atau menyajikan makanan (bekal sekolah anak) bahwa 80\% wali siswa mendaptkan nilai tinggi. Dengan dilaksanakannya pelatihan dan pemberdayaan walisiswa dapat menerapkan bekal makanan sehat untuk anaknya.
\end{abstract}

Kata Kunci: Gizi, Pengolahan Makanan, Orang Tua/Wali

\begin{abstract}
Providing training and empowerment for student's Parents to serve healthy food is necessary to improve the nutrition in children food from an early age. Early childhood is very susceptible to various diseases, especially those from food. It requires supervision, especially parents in providing food for children which is health and has a good nutrition. The purpose of this activity is to increase parents' knowledge about how to process healthy food and nutritious for children, and improve skills in preparing or serving food (children's school supplies). The method of this activity is collaborating with related agencies, such as the Centre of Community Services (PKM) to organize the socialization to student's Parents/guardians about how to process food and prepare good food. The socialization involves kindergarten teachers. The results of this activity shows that $75 \%$ of students's Parents/guardians, get a higher knowledge about how to process healthy and nutritious food for children, and $80 \%$ of students's Parents/guardians, get high grades for skill on preparing or serving food (children's school supplies).
\end{abstract}

Keyword: Nutrition, Food Processing, Students' Parents/Guardians 


\section{PENDAHULUAN}

Gizi merupakan salah satu aspek yang sangat penting dalam pertumbuhan dan perkembangan anak usia dini. Pemenuhan gizi yang cukup pada anak di usia awal (0-6 tahun) dapat mempengaruhi perkembangan mental, termasuk kecerdasan anak. Kesehatan dan gizi anak sangatlah penting untuk diperhatikan, sejak dari dalam kandungan hingga lahir. Hal ini dikarenakan, kesehatan dan gizi sangat mempengaruhi pertumbuhan dan perkembangan anak. Anak yang mendapatkan gizi yang seimbang serta makanan yang sehat, akan tumbuh menjadi manusia yang berkualitas, begitu pula sebaliknya (Arisman, M.B, 2010).

Menurut Sulistyoningsih, (2011) asupan nutrisi pada anak memegang peranan penting dalam optimalisasi tumbuh kembang pada anak. Keadekuatan asupan nutrisi pada anak dapat dinilai dengan keadaan status gizi yang ditandai dengan anak kurus, normal, dan gemuk (Supriasa, 2012). Pada umumnya masalah kesehatan yang sering dialami anak-anak adalah kurang gizi, pola makan. Gizi sangat mempengaruhi perkembangan anak. Masalah pola makan sangat berkaitan erat dengan hal ini. Apalagi sekarang ini sudah banyak makanan yang cepat saji (instan), yang di dalamnya terdapat zat kimia yang berbahaya bagi kesehatan manusia bila dikonsumsi terus menerus dalam jangka waktu yang lama. Untuk itu peranan pendidikan pada orang tua dapat membantu dalam menciptakan kualitas anak dimasa yang akan datang (Purwani, 2013).

Salah satu peran orang tua adalah bertanggung jawab atas pemenuhan nutrisi pada anaknya, keinginan orang tua untuk memenuhi kebutuhan nutrisi anaknya sering kali melatar belakangi praktik pemberian makan yang kurang tepat. Praktik pemberian makan yang kurang tepat antara lain selalu memenuhi kemauan anak untuk mengkonsumsi makanan yang ia inginkan, bahkan orang tua banyak yang membiarkan apapun makanan yang dikonsumsi anaknya, banyak orangtua yang menyajikan makanan siap saji (Sulistyoningsih, 2011).

Demikian halnya yang terjadi di TK Khadijah 87, Wali Siswa (orang tua) masih kurang memperhatikan status gizi anak serta cara pengolahan makanan yang kurang sehat, membawakan bekal nasi, telur dan mie instan. Masih banyak orang tua yang menyajikan makanan siap saji hampir setiap hari, sesuai keinginan anak yang penting anak mau makan.

Pentingnya kegiatan ini untuk meningkatkan pengetahuan wali siswa (orang tua) di TK Khajidah 87 tentang cara pengolahan makanan yang sehat dan bergizi bagi anak, serta meningkatkan keterampilan dalam menyiapkan atau menyajikan makanan (Bekal sekolah anak). Orang tua juga bertanggung jawab memenuhi kebutuhuan nutrisi anak dengan cara memberikan makanan yang bergizi, sehat dan berusaha membatasi makanan cepat saji bagi anak.

Mitra yaitu wali siswa dan guru TK Khadijah Kalibaru Kulon, wali siswa yang ikut direncanakan berjumlah 40 orang dan guru 4 orang guru. Wali siswa yang ikut pelaksanaan yaitu wali siswa yang dapat berkomunikasu dengan baik, sehat, aktif dan setuju mengikuti pelatihan tersebut..

\section{METODE PENELITIAN}

Kegiatan ini dilaksanakan selama 4 bulan mulai April 2018 - Juli 2018 di Desa Kalibaru Kulon Kecamatan Kalibaru Kabupaten Banyuwangi yaitu TK Khadijah 87 Kalibaru Langkah-langkah kegiatan Pelatihan ini adalah;

\section{A. Persiapan program}

Persiapan program pelatihan penyajian makanan sehat yang pertama dilakukan adalah pendekatan dengan Kepala Sekolah TK Khadijah 87 sekaligus melakukan survey. Survey 
dilakukan dengan mengumpulkan bukti terkait bekal makanan yang dibawa anak sekolah termasuk makanan sehat atau tidak. Data yang dibutuhkan adalah jumlah siswa yang membawa bekal makanan, menu yang disajikan orang tua wali siswa agar pelaksanaan program pelatihan tentang makanan sehat berjalan lancar.

Penilaian strategis lokasi dilakukan dengan melihat kondisi sekolah dan masalah kesehatan yang terjadi. Peralatan dan bahan meliputi penentuan media yang paling tepat untuk sosialosasi kepada orang tua wali siswa dan materi informasi yang mudah diserap oleh orang tua wali siswa. Pelaksanaan program perawat cilik mencakup juga melakukan perjajian kepada sekolah dan guru untuk mendukunng dan membantu kelancaran jalannya program hingga pelaksanaan program berakhir.

B. Persiapan Alat

Persiapan alat yang dibtutuhkan dalam acara pelatihan yang terdiri dari sosialisasi dan paktek adalah:
a. Laptop, LCD dan layar
b. Karpet
c. Sound system dan mix
d. Meja
e. Buku Modul
f. Peralatan praktek untuk memasak menu masakan sehat

C. Pelaksanan Program

Pelaksanan program yaitu pelatihan dengan ceramah dan diskusi tentang makanan sehat dan bergizi pada anak yang dilaksanakn di TK Khadijah 87 dengan kriteria srana dan prasaranan yang memadai. Kegiatan ini diikuti oleh wali siswa siswa siswi Tk Khadijah 87 berjumlah 40 wali siswa dan ditambah 4 guru agar mengetahui proram yang telah dilakukan. Program dijalankan oleh tim Akademi Kesehatan Rustida yang terdiri dari dosen dan mahasiswa. Metode yang diterapkan ceramah, diskusi, dan demonstrasi. Kegiatan pendampingan ini dilakukan kepada sasaran mulai dari pemaparan materi tentang:

a. Definisi makanan sehat dan bergizi

b. Fungsi utama makanan

1) Untuk memberikan tenaga atau energi tubuh

2) Untuk pertumbuhan maupun perbaikan sel tubuh yang rusak

3) Mengatur metabolism tubuh

c. Ciri-ciri makanan sehat

1) Mengandung cukup zat gizi

2) Tidak mengandung zat-zat berbahaya(pengawet, pewarna, penyedap rasa)

3) Sedikit mengandung minyak

d. Kandungan makanan sehat dan bergizi, contoh makanan sehat dan bergizi, contoh makanan tidak sehat, dampak makan tidak sehat, contoh cara membuat makanan sehat.

\section{Evaluasi}

Evaluasi dilakukan dalam dua tahap yaitu evaluasi jangka pendek dan jangka panjang

a. Evaluasi jangka pendek yaitu yang dilakukan stelah acara pelatihan selesai wali siswa diberi beberapa pertanyaan dan disuruh menjawab dengan benar. Evaluasi dilaksanakan untuk mengetahui keefektifan dari program pelatihan memasak makanan sehat dan untuk mengetahui tingkat pemahaman wali siswa terhadap materi yang telah diberikan. 
b. Evaluasi jangka panjang dilakukan pada minggu ke 12 setelah pelatihan berlangsung. Evaluasi ini untuk mengetahui apakah pelatihan tersebut bermanfaat sekali serta diilaksanakan disekolah. Dan untuk mengukur keberhasilan kegiatan PKM adalah lembar observasi terkait bekal yang dibawa siswa siswi termasuk makanan sehat.

E. Bentuk Kegiatan

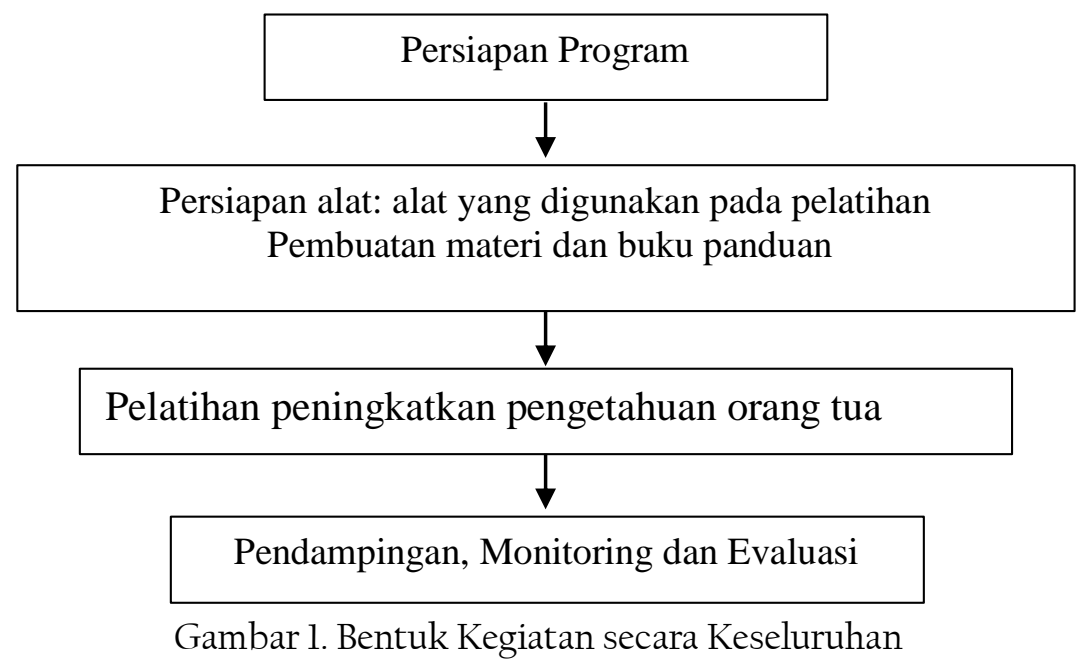

III. HASIL DAN PEMBAHASAN

Program Pelatihan ini dilakukan secara terstruktur dan melibatkan guru dan orangtua secara langsung. jumlah peserta yang mengikuti pelatihan ini adalah 40 orang tua wali siswa dan 4 orang guru.

\section{A. Hasil}

Berdasarkan pengabdian kepada masyarakat yang telah dilakukan akan menyajikan data yang telah dilakukan, pelaksana akan menyajikan data yang tealh dikumpulkan dalam bentuk presentase dan tabel

1. Karakteristik Wali Siswa Berdasarkan Jenis Kelamin

Bahwa jumlah wali siswa (orang tua) yang mengikuti pelatihan $100 \%$ perempuan sejumlah 40 orang.

2. Hasil Kegiatan

a. Pengetahuan orang tua tentang Definisi makanan sehat dan bergizi, Fungsi utama makanaan, Ciri-ciri makanan sehat, Kandungan makanan sehat dan bergizi, contoh makanan sehat dan bergizi, contoh makanan tidak sehat, dampak makan tidak sehat, contoh cara membuat makanan sehat. 


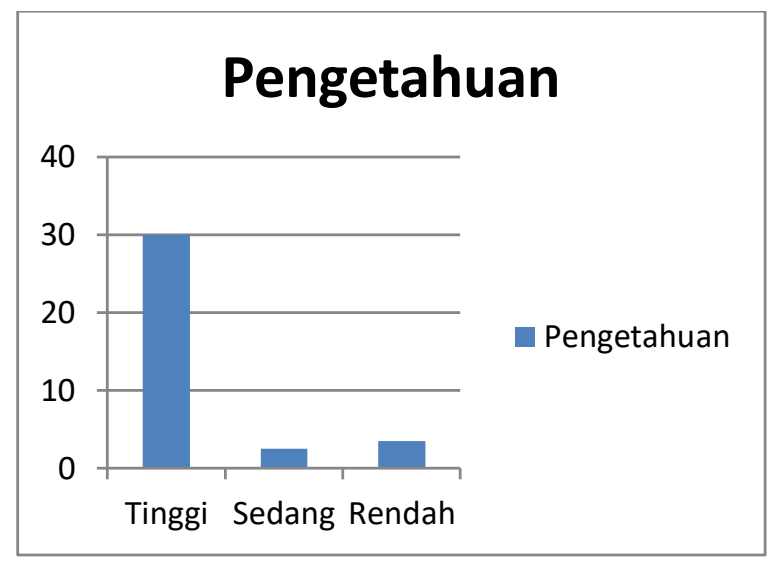

Gambar 2. Pengetahuan orang tua tentang makan sehat dan bergizi

Berdasarkan gambar diatas bahwa setelah orang tua wali siswa mendapatkan pelatihan. Bahwa pengetahuan orang tua tentang makanan sehat dan bergizi sebagian besar $75 \%$ mendaptkan nilai tinggi

b. Praktek cara membuat makan sehat dan bergizi

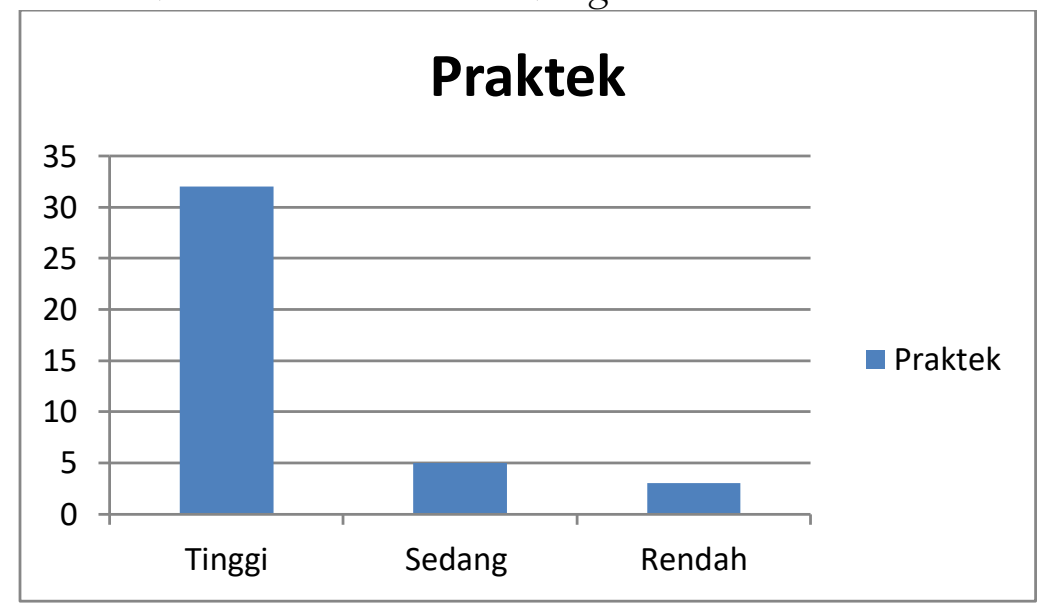

Gambar 3. Praktek membuat bekal makan sehat dan bergizi

Berdasarkan gambar diatas bahwa setelah orang tua wali siswa mendapatkan pelatihan. Bahwa keterampilan orang tua tentang cara membuat makanan sehat dan bergizi sebagian besar $80 \%$ mendaptkan nilai tinggi

\section{B. Pembahasan}

Target peserta pelatihan seperti direncanakan sebelumnya adalah paling tidak wali siswa (orang tua) yang berjumlah 40 orang, kegiatan ini diikuti oleh 40 wali siswa. Dengan demikian dapat dikatakan bahwa target peserta tercapai 100\%. Angka tersebut menunjukkn bahwa kegiatan Pengabdian kepada Masyarakat dilihat dari jumlah peserta yang mengetahui dapat dikatakan berhasil atau sukses.

Ketercapaian tujuan pendampingan pengembangan dan pembelajaran secara umum sudah baik, materi yang telah disampaikan secara detail kepada seluruh peserta. Hal ini dapat dilihat dari pemahaman wali siswa (orang tua) tentang materi yang disampaikan baik materi tentang makanan sehat dan bergizi pada anak, dan praktek tentang pengolahan dan penyajian makanan sehat dan bergizi pada anak. 


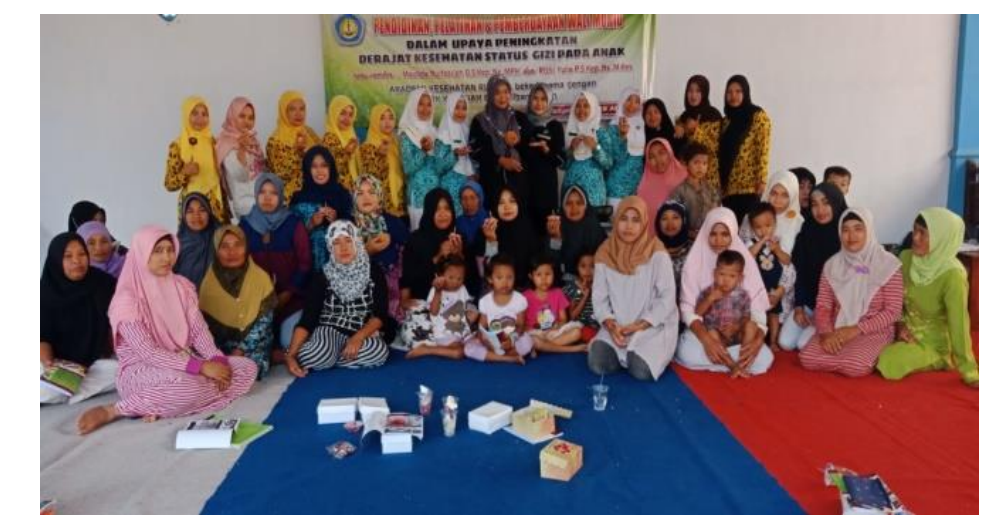

Gambar 4. Pemberian materi tentang makan sehat dan bergizi

Ketercapaian target materi pada kegiatan Pengabdian kepada Masyarakat ini cukup baik, karena materi pendampingan telah dapat disampaikan secara keseluruhan. Materi pendampingan yang telah disampaikan adalah: apakah itu makanan sehat dan bergizi. fungsi utama makanan, ciri-ciri makanan sehat dan bergizi, kandungan makanan sehat dan bergizi, contoh makanan sehat dan bergizi, contoh makanan tidak sehat, dampak makan tidak sehat, contoh cara membuat makanan sehat

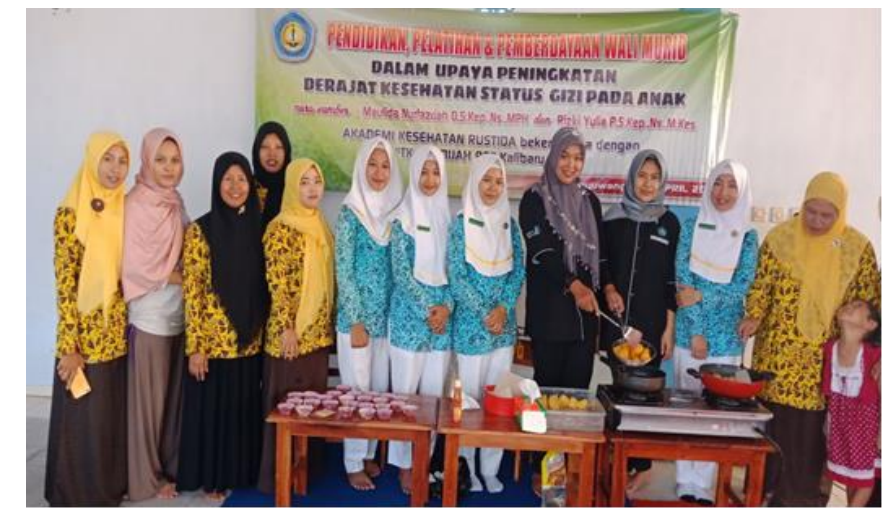

Gambar 5. Praktek membuat makanan sehat dan bergizi

Kemampuan wali siswa (orang tua) dilihat dari penguasaan materi sudah baik, antusias wali siswa dalam memperhatian meteri, dan memperhatikan fasilitator dalam mempraktekan membuat makanan sehat bergizi, bekal anak sekolah. Secara keseluruhan kegiatan pelatihan makanan bergizi dan sehat dapat dikatakan berhasil. Keberhasilan ini selain diukur dari keempat komponen diatas, juga dapat dilihat dari kepuasan wali siswa setelah mengikuti kgiatan. Manfaat yang diperoleh bagi wali siswa (orang tua) adalah meningkatkan pengetahuan orang tua tentang cara pengolahan makanan yang sehat dan bergizi bagi anak, dan meningkatkan keterampilan dalam menyiapkan atau menyajikan makanan (bekal sekolah anak).

\section{PENUTUP}

A. Kesimpulan

Berdasarkan hasil pengabdian kepada masyarakat yang telah dilakukan, dapat diambil beberapa kesimpulan, antara lain:

1. Seluruh wali siswa yang hadir mengikuti kegiatan pelatihan

2. Pengetahuan wali siswa menjadi lebih baik, setelah diberikan pndidikan tentang makanan sehat dan bergizi pada anak dan 
3. Seluruh wali siswa telah memahami dan dapat mendemonstrasikan makanan sehat dan bergizi pada anak.

$$
\text { B. Saran }
$$

1. Perlu ada tindak lanjut dan monitoring pengetahuan wali siswa (orang tua) tentang menu makanan sehat.

2. Perlu ada tindak lanjut dan monitoring perilaku wali siswa (orang tua) dalam menyiapkan makanan bekal sekolah anak.

\section{DAFTAR PUSTAKA}

Arisman, M.B. (2010). Buku Ajar Ilmu Gizi Dalam Daur Kehidupan. Edisi-2. Jakarta: EGC

Purwani, E. (2013). Pola mberian Makan dengan Staus Gizi Anak Usia 1 sampai 5 Tahun dikabunan Taman Pemalang. Fakultas Ilmu Keperawatan dan Kesehatan Universitas Muhammadiyah Semarang

Sulistyoningsih. (2011). Pertumbuhan dan Perkembangan Anak dan Remaja. Jakarta: TIM

Supriasa, et al. (2013). Penilain Status Gizi. Jakarta : EGC 